\title{
Cats Infected by Feline Leukemia Virus-Morpho-Quantitative Evaluation of the Thymus
}

\author{
Flávia Azevedo Cavalcanti de Melo, Anna Clara dos Santos, Kaique Nogueira*, \\ André Rodrigues da Cunha Barreto-Vianna, Eduardo Maurício Mendes de Lima \\ Faculty of Agronomy and Veterinary Medicine, University of Brasilia, Brasília, Brazil \\ Email: ${ }^{*}$ kiqnogueira@gmail.com
}

Received 2 May 2015; accepted 3 July 2015; published 6 July 2015

Copyright (C) 2015 by authors and Scientific Research Publishing Inc.

This work is licensed under the Creative Commons Attribution International License (CC BY). http://creativecommons.org/licenses/by/4.0/

c) (i) Open Access

\section{Abstract}

The feline leukemia virus (FeLV) is a complex disease that affects mainly the immune and hematological systems of cats. And because the thymus was closely associated with the immune system, the aim of this study was to quantify the morphological changes in the thymus of naturally infected and uninfected animals. Thymus morphological changes were evaluated by quantifying the following parameters: thymocytes, fat tissue, thymic corpuscles, connective tissue, and type I and III collagen. This study analyzed a total of seven cats, five in the negative group (Fn) and two in the positive (Fp) group. The areas occupied by thymocytes in FeLV negative (Fn) and positive (Fp) animals were, respectively, $55.16 \% \pm 6.15 \%$ and $44.81 \% \pm 6.15 \%(p=0.39)$; adipocytes, $42.14 \% \pm$ $5.97 \%(F n)$ and $53.42 \% \pm 11.3 \%$ (Fp) (p = 0.34); blood vessels, $0.85 \% \pm 0.24 \%$ (Fn) and $1.75 \% \pm$ $0.52 \%(F p)(p=0.15)$. Whereas thymic corpuscles occupied an area of $0.68 \% \pm 0.19 \%$ in negative animals (Fn) only. The connective tissue covered area varied between $12.05 \% \pm 0.68 \%$ (Fn) and $10.34 \% \pm 0.62 \%(F p)(p=0.009)$. Collagen type I $(p=0.30)$ and type III $(p=0.59)$ were present in, respectively, $1.73 \% \pm 0.3 \%$ and $0.44 \% \pm 0.09 \%$ in $F n$, and $1.44 \% \pm 0.36$ and $0.44 \% \pm 0.13 \%$ in Fp. The FeLV virus was not able to completely modify the thymus structure of infected animals, considering the areas occupied by thymocytes, adipose tissue, blood vessels and also type I and III collagens. However, the connective tissue underwent a certain degree of remodeling since less connective tissue area was observed in FeLV infected animals. The absence of thymic corpuscles in immunosuppressed animals suggests a possible connection to thymopoiesis.

\section{Keywords}

Domestic Cats, Morphology, Lymphoid Organ, FeLV

\footnotetext{
${ }^{*}$ Corresponding author.
}

How to cite this paper: Melo, F.A.C., Santos, A.C., Nogueira, K., Barreto-Vianna, A.R.C. and Lima, E.M.M. (2015) Cats Infected by Feline Leukemia Virus-Morpho-Quantitative Evaluation of the Thymus. Open Journal of Animal Sciences, 5, 277-282. http://dx.doi.org/10.4236/ojas.2015.53032 


\section{Introduction}

Feline Leukemia Virus (FeLV) belongs to the Gammaretrovirus genus, Retroviridae family and causes an important disease routinely diagnosed in domestic cats [1]. Infection usually occurs in the oropharynx due to prolonged direct contact, especially through mutual grooming, sharing water and feed bowls. After infection of the oropharynx, the virus infects the lymphocytes, reaching the bone marrow [2]. The infected cells carry the viral agent to other target tissues such as thymus, spleen and lymph nodes [3].

The FeLV infection course depends on factors such as the host immune response and disease progression. It is known to cause a variety of neoplastic and non-neoplastic diseases in domestic cats (Felis catus), such as thymic lymphoma, multicentric lymphoma, myelodysplastic syndromes, acute myeloid leukemia, aplastic anemia, and immunodeficiency ([4]-[10]).

The thymus is an important organ in FeLV infection because it is a lymphoid organ whose primary function is to provide a proper environment for $\mathrm{T}$ lymphocytes differentiation, maturation, and selection, from the migrant progenitor cells of the bone marrow [11].

Therefore, this study evaluated the morphological changes in the thymus, an important lymphoid organ targeted by the virus, by quantifying the thymocytes, fat tissue, thymic corpuscles, connective tissue, and type I and III collagen fibers of naturally infected and uninfected cats.

\section{Materials and Methods}

Seven domestic cats (Felis catus domesticus) seen at the Veterinary Hospital of the Universidade de Brasilia were divided into two groups and evaluated. The FeLV-positive group (Fp) had two cats (one male and one female) and the FeLV-negative (Fn) group had five cats (two males and three females). The Fp cats were positive only for FeLV infection (not for FIV infection) and were diagnosed with anemia and leukopenia according to Complete Blood Count (CBC) results. The Fn cats were negative for both FIV and FeLV infection and the Complete Blood Count (CBC) results were normal. The study was approved by the Animal Use Ethics Committee of the University of Brasília $(\neq 109508 / 2011)$.

Both animals of the Fp group had FeLV infection symptoms such as decreased appetite and prostration, in addition to severe anemia (Corpuscular Volume 9\%). The infection was confirmed by the SNAP FeLV/FIV Combo Test (INDEXX Laboratories). The animals' age ranged between six months and three years.

The thoracic lobes of the thymus of both antimeres were collected immediately after the animals' death. To this end, two longitudinal sections were performed along the ninth intercostal space in both antimeres to visualize the corresponding thoracic lobes of the thymus. The thymic mass was considered as a single structure without differentiating between the lobes, which was justified by the age of the animals. In general, some right thoracic lobes were already in advanced involution stage, or even absent.

The thymuses were sectioned transversely along serial and parallel macroscopic plans distant $3 \mathrm{~mm}$ average. The modified guiding method was followed to obtain IUR (isotropic, uniform and random) sections. The fragments were immersed in $10 \%$ formaldehyde fixative solution for at least 24 hours, embedded in paraffin, and subjected to conventional histological techniques. The $4 \mu \mathrm{m}$-thick sections were obtained using a manual microtome (Leica RM 2125RT). The Hematoxylin-Eosin stained slides were used to quantify the area occupied by

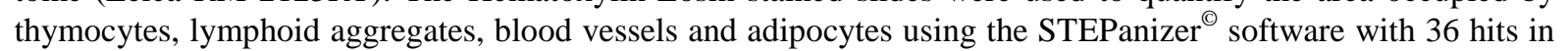
the grid. The total area was calculated after counting the hits according to the Delesse principle, where $A_{\text {[est] }}$ is the area occupied by the structure; $\mathrm{R}_{\text {[est] }}$, the number of hits counted per structure; and $\mathrm{P}_{\mathrm{t}}$, total number of hits in the grid. Furthermore, the samples stained with Pricrosirius red were used to determine the proportion of connective tissue between groups, to differentiate type I and III collagen fibers using the polarizing filter and Image Pro Plus $6.0^{\circledR}$ image analysis software. Photomicrographs of random fields of each fragment were obtained using an Olympus BX51 optical microscope coupled to the ProgRes ${ }^{\circledR}$ Capture Pro 2.5 image analysis and capture software.

Data are presented as means and standard deviations. The data were submitted to Kolmogorov-Smirnov normality test and compared by Mann-Whitney test, besides Pearson and Spearman correlation (GraphPad Prism 2.6 for Windows, GraphPad Software, San Diego, CA, USA), at $\mathrm{p}<0.05$ significance level.

\section{Results}

The thymocytes occupied areas were 55.16\% \pm 6.15\% and $44.81 \% \pm 6.15 \%$ for Fn and Fp groups, respectively 
(Figures $1(\mathrm{~A})$ ), with $\mathrm{p}=0.34$. On the other hand, adipose tissue behaved inversely to thymocytes and the occupied areas were $42.14 \% \pm 5.97 \%$ and $53.42 \% \pm 11.3 \%$ in animals of $\mathrm{Fn}$ and Fp groups, respectively (Figure 1(B)). The adipose tissue formed "islands" defined by the presence of tissue extensions in both groups. The proportion of blood vessels varied between $0.85 \% \pm 0.24 \%$ in Fn animals and $1.76 \% \pm 0.52 \%$ in Fp (Figure $1(C)$ ) animals, with $\mathrm{p}=0.15$.

Thymic corpuscles presence was $0.68 \% \pm 0.19 \%$ in Fn cats while absent in Fp animals.

The amount of connective tissue in the thymus varied between $12.05 \% \pm 0.68 \%$ in the Fn animals and $10.34 \%$ $\pm 0.67 \%$ in Fp animals (Figure 1(D)), with $\mathrm{p}=0.009$.

Figure 1(E) and Figure 1(F) show that type I and type III collagen fibers covered an area ranging between $1.73 \% \pm 0.3 \%$ and $0.44 \% \pm 0.09 \%$ in Fn animals $(p=0.30$ ); and $1.44 \% \pm 0.36 \%$ and $0.44 \% \pm 0.13 \%$ in Fp cats $(\mathrm{p}=0.59)$. Type I collagen was predominant in the thymus of both groups, suggesting that this is related to the structural arrangement of the organ.

The disposition of thymocytes and adipose tissue for Fn and Fp groups is shown in Figure 2(A) and Figure 2(B), and Figure 3(A) and Figure 3(B), respectively. Thymic corpuscle for Fn group is shown in Figure 2(C). The blood vessels for Fn and Fp groups are shown in Figure 2(D) and Figure 3(C), respectively. The connective tissue for Fn and Fp groups is shown in Figures 2(E) and Figure 3(D), respectively; lastly, the disposition of Collagens I and III for Fn group is shown in Figure 2(E).

\section{Discussion}

Structural changes throughout the thymic development and involution were evidenced in domestic animals [11] [12]. This fact was evident by the organ architectural and physiological changes, in addition to the reducing thymus. The changing structure of the thymus justified the arrangement found regarding the different component

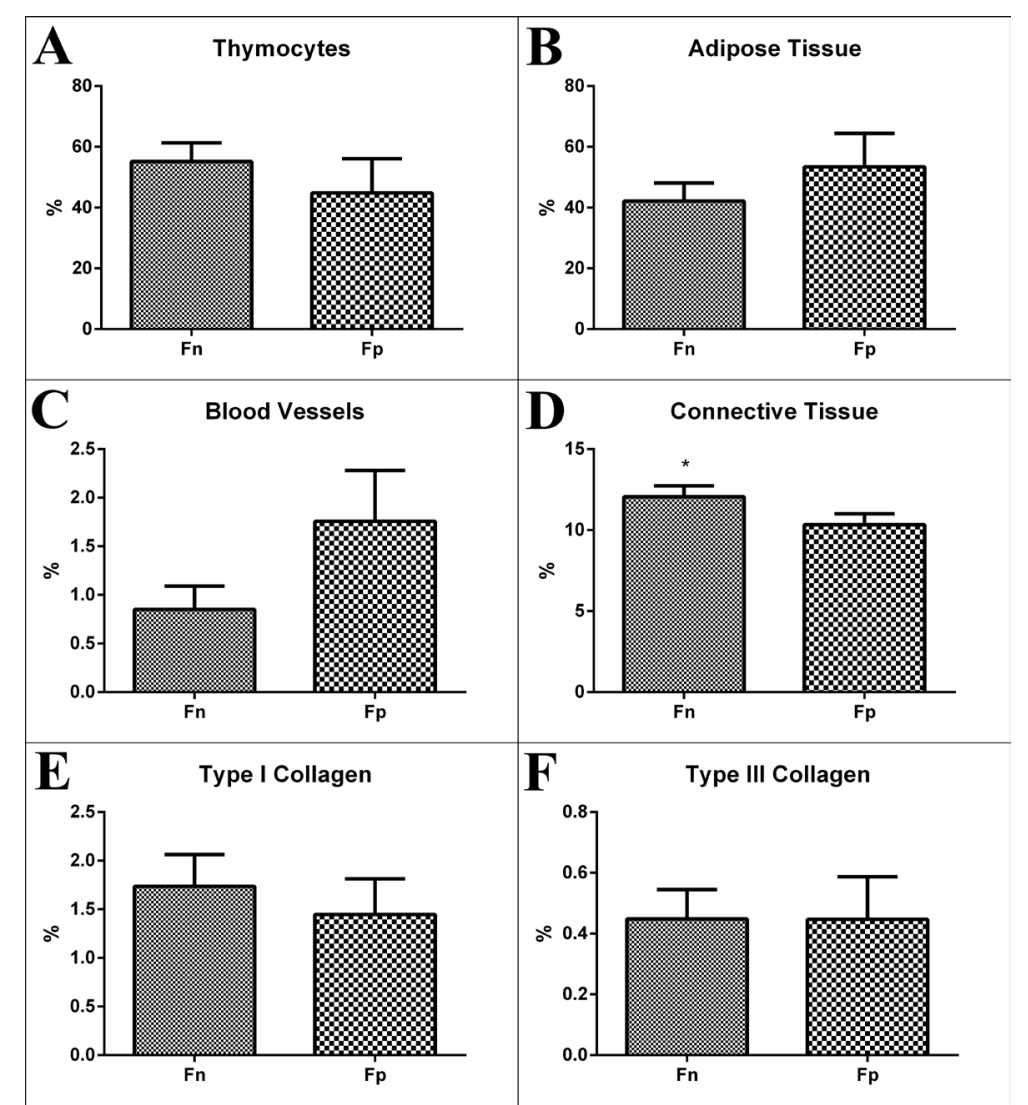

Figure 1. Percentage (\%) of thymocytes (A), fat tissue (B), blood vessels (C), connective tissue (D), type I (E) and type III (F) collagens for FeLV negative (Fn) and positive (Fp) cats. The asterisk shows significant difference between groups, according to the Wilcoxon test results. 


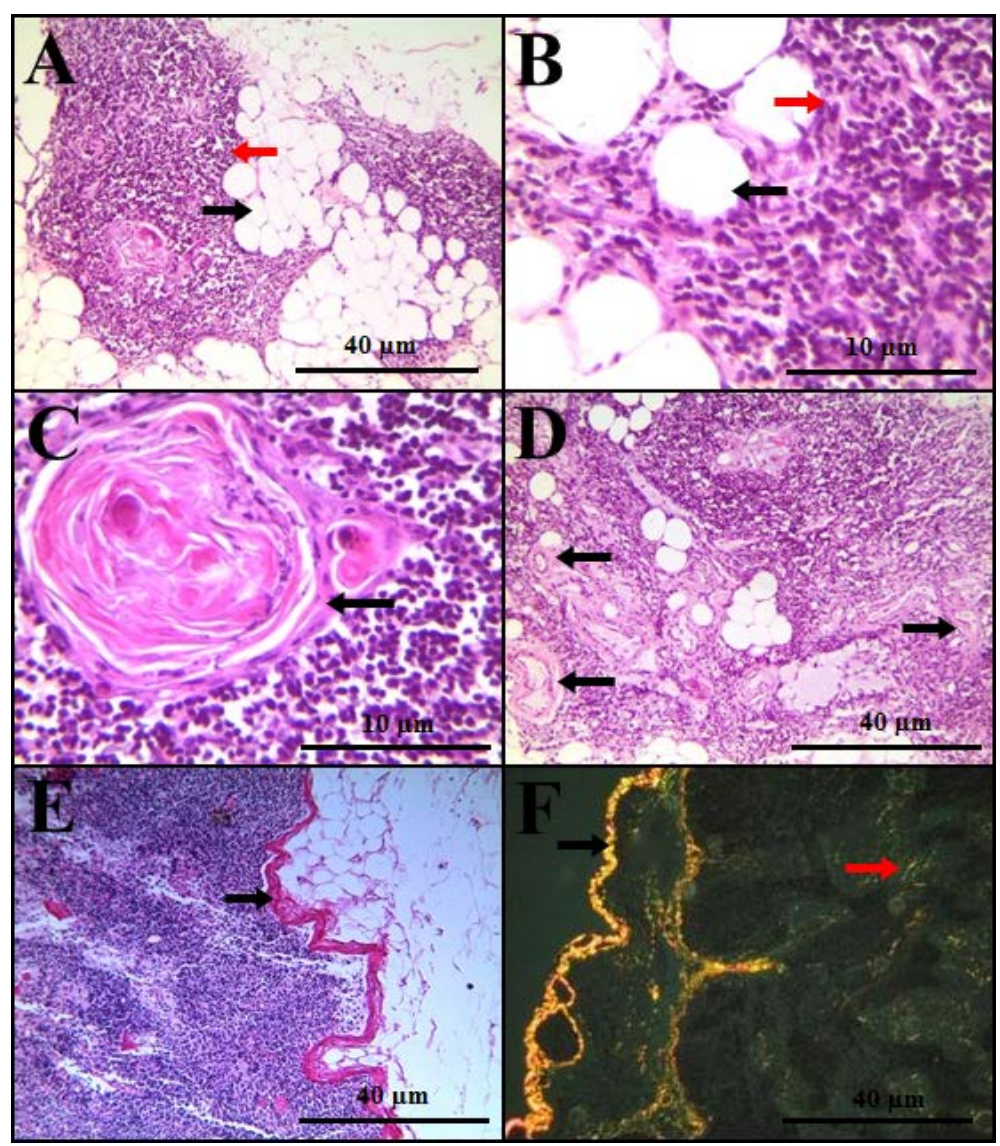

Figure 2. FeLV-Negative Group: HE-stained photomicrograph showing adipose tissue (black arrow) and thymocytes (red arrow) in images (A) and (B); thymic corpuscle (black arrow), in image (C) and blood vessels (black arrows) in image (D); Picrosirius-stained photomicrograph showing connective tissue (black arrow) in image (E); Polarized light photomicrograph showing type I collagen (black arrow) and type III collagen (red arrow) in image (F).

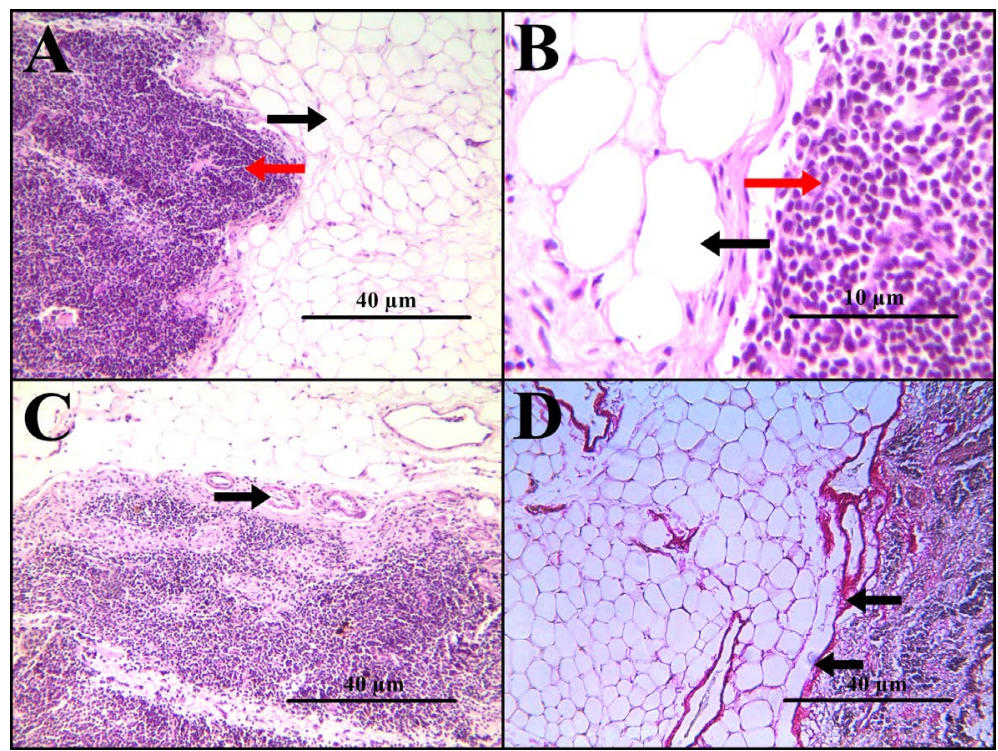

Figure 3. FeLV-Positive Group: HE-stained photomicrograph showing adipose tissue (black arrow) and thymocytes (red arrow) in images (A) and (B); blood vessels (black arrows) in image (C); Picrosirius-stained photomicrograph showing connective tissue (black arrow) in image (D). 
tissues. Lima and Carneiro-Sampaio (2007) [11] stated that the amount of adipose tissue in the body increases with age, which could explain the percent increase of adipose tissue disposition in Fp group since the animals of this group were older than the cats in the Fn group.

Thymic corpuscles were found only after 50 days of gestation in cats [13] and between the 30th day of gestation and one year of age in dogs [14]. The time-dependency of these structures is documented in the literature, their function, however, has not yet been clarified. The findings in feline and other species vary. However, studies evaluating VEGF (vascular endothelial growth factor) presence in human thymus corroborate the hypothesis of active participation of these corpuscles in thymopoiesis [15]. In addition, the presence of the FeLV virus suggests that thymus atrophy did not play a role in thymopoiesis, and that the decrease of thymocytes in cats of the Fp group was probably due to the absence of thymic corpuscles. The loss of thymic epithelial cells and the increase in both perivascular space-usually infiltrated by adipocytes-and cystic cavities were strong characteristics of thymus physiological involution, which were especially expressed by thymocytes involution [16].

The connective tissue decreased in the cats of the Fp group compared to those of the Fn group. This result suggests that there was remodeling of connective tissue due to the disease. In young animals (up to 55 days), the thymic corpuscle capsule consists of connective tissue [13]. So, it was possible to suggest also that the thymic corpuscles present in cats of the Fp group are closely related to the increased connective tissue in the group.

The remodeling of the connective tissue only in cats of the Fp group suggests that the functional changing process of the organ had started, but it was interrupted by the immunosuppressive activity of the disease. In other words, the convalescent state of the animals acted only as a precursor to the tissue deposition while the maintenance and concrete replacement could not be completed.

\section{Conclusion}

The FeLV virus was unable structurally to modify the thymus of naturally infected animals, considering the results obtained for thymocytes, adipose tissue, blood vessels, and type I and III collagens. The statistically significant lesser amount of connective tissue found in animals infected with FeLV indicated tissue remodeling due to the disease. The absence of thymic corpuscles in immunosuppressed animals led to believe that these structures were linked to thymopoiesis.

\section{References}

[1] Dunham, S.P. and Graham, E. (2008) Retroviral Infections of Small Animals. Veterinary Clinics of North America: Small Animal Practice, 38, 879-901. http://dx.doi.org/10.1016/j.cvsm.2008.03.005

[2] Lutz, H., Addie, D., Belák, S., Boucraut-Baralon, C., Egberink, H., Frymus, T. and Horzinek, M.C. (2009) Feline Leukaemia. ABCD Guidelines on Prevention and Management. Journal of Feline Medicine and Surgery, 11, 565-574. http://dx.doi.org/10.1016/j.jfms.2009.05.005

[3] Levy, J.K. (2004) VLF e doença não-neoplásica relacionada. In: Ettinger, S.J. and Feldman, E.C., Eds., Tratado de Medicina Interna Veterinária, Guanabara Koogan, 5th Edition, Rio de Janeir, 446-455.

[4] Hisasue, M., Nagashima, N., Nishigaki, K., Fukuzawa, I., Ura, S., Katae, H., Tsuchiya, R., Yamada, T., Hasegawa, A. and Tsujimoto, H. (2009) Myelodysplastic Syndromes and Acute Myeloid Leukemia in Cats Infected with Feline Leukemia Virus Clone33 Containing a Unique Long Terminal Repeat. International Journal of Cancer, 124, 1133-1141. http://dx.doi.org/10.1002/ijc.24050

[5] Rohn, J.L., Linenberger, M.L., Hoover, E.A. and Overbaugh, J. (1994) Evolution of Feline Leukemia Virus Variant Genomes with Insertions, Deletions, and Defective Envelope Genes in Infected Cats with Tumors. Journal of Virology, 68, 2458-2467.

[6] Tzavaras, T., Stewart, M., McDougall, A., Fulton, R., Testa, N., Onions, D.E. and Neil, J.C. (1990) Molecular Cloning and Characterization of a Defective Recombinant Feline Leukaemia Virus Associated with Myeloid Leukaemia. Journal of General Virology, 71, 343-354. http://dx.doi.org/10.1099/0022-1317-71-2-343

[7] Overbaugh, J., Donahue, P.R., Quackenbush, S.L., Hoover, E.A. and Mullins, J.I. (1988) Molecular Cloning of a Feline Leukemia Virus That Induces Fatal Immunodeficiency Disease in Cats. Science, 239, 906-910. http://dx.doi.org/10.1126/science.2893454

[8] Miura, T., Tsujimoto, H., Fukasawa, M., Kodama, T., Shibuya, M., Hasegawa, A. and Hayami, M. (1987) Structural Abnormality and Over-Expression of the Myc Gene in Feline Leukemias. International Journal of Cancer, 40, 564569. http://dx.doi.org/10.1002/ijc.2910400422

[9] Rojko, J.L., Hoover, E.A., Mathes, L.E., Olsen, R.G. and Schaller, J.P. (1979) Pathogenesis of Experimental Feline 
Leukemia Virus Infection. Journal of National Cancer Institute, 63, 759-768.

[10] Mackey, L., Jarrett, W., Jarrett, O. and Laird, H. (1975) Anemia Associated with Feline Leukemia Virus Infection in Cats. Journal of National Cancer Institute, 54, 209-217.

[11] Lima, F.A. and Carneiro-Sampaio, M. (2007) O papel do timo no desenvolvimento do sistema imune. Pediatria (São Paulo), 29, 33-42.

[12] Agreste, F.R., Moriconi, P.R., Barreto-Vianna, A.R.C., Santos-Leonardo, A., Bombonato, P.P. and Lima, E.M.M. (2013) Is the Vascular Growth Curve of Thymus of Dogs (Canis familiaris) Time-Dependent? Australian Journal of Basic and Applied Sciences, 7.

[13] Agreste, F.R., Bombonato, P.P. and Hernandez-Blazquez, F.J. (2007) Características mor Características morfométricas do desenvolvimento do timo fométricas do desenvolvimento do timo em cães1. Pesquisa Veterinária Brasileira, 27, 236-240. http://dx.doi.org/10.1590/S0100-736X2007000600003

[14] Cimpean, A.M., Raica, M., Encica, S., Cornea, R. and Bocan, V. (2008) Immunohistochemical Expression of Vascular Endothelial Growth Factor A (VEGF), and Its Receptors (VEGFR1, 2) in Normal and Pathologic Conditions of the Human Thymus. Annals of Anatomy-Anatomischer Anzeiger, 190, 238-245. http://dx.doi.org/10.1016/j.aanat.2007.05.003

[15] Hince, M., Sakkal, S., Vlahos, K., Dudakov, J., Boyd, R. and Chidgey, A. (2008) The Role of Sex Steroids and Gonadectomy in the Control of Thymic Involution. Cellular Immunology, 252, 122-138. http://dx.doi.org/10.1016/j.cellimm.2007.10.007

[16] Barroso, C.E. (2012) Desenvolvimento embrionário tímico em fetos de gatos domésticos (Felis domesticus). Biotemas, 25, 239-247. http://dx.doi.org/10.5007/2175-7925.2012v25n3p239 